Valuation Studies 8(1) 2021:33-66

\title{
Valuation Constellations
}

\author{
Désirée Waibel,Thorsten Peetz, and Frank Meier
}

\begin{abstract}
The focus on situated practices in current valuation studies becomes an obstacle when situations are too narrowly defined, when moments of valuation are treated as isolated events and especially when the interconnectedness of moments across situations and social fields is neglected. In order to overcome these limitations, we propose the concept of valuation constellations (Meier et al. 2016). Based on the literature on valuation the concept distinguishes positions and their relations, rules, and infrastructures. We present these three components of constellations and demonstrate the potential of the concept regarding three analytical puzzles of valuation analysis: historical change of valuation processes, the definition and solution of valuation problems, and the legitimacy of valuations. Each of the puzzles is illustrated with an empirical case, i.e. dating platforms and apps, higher education, and amateur reviewing. Going beyond situationalism, the valuation constellations perspective is key to understanding interconnected valuation processes.
\end{abstract}

Keywords: sociology of valuation; valuation constellations; linked valuations; positions; rules; infrastructures

Désirée Waibel, SOCIUM - Research Center on Inequality and Social Policy,

University of Bremen, Germany. desiree.waibel@uni-bremen.de

Thorsten Peetz, Hanse-Wissenschaftskolleg (Institute for Advanced Study), Germany

peetz@uni-bremen.de

Frank Meier,frank.meier@hsu-hh.de

(C) 2021 The authors

(cc) BY-No This work is licensed under a Creative Commons Attribution-

NonCommercial 4.0 International License.

bttps://doi.org/10.3384/VS.2001-5992.2021.8.1.33-66

Hosted by Linköping University Electronic press

http://valuationstudies.liu.se 


\section{Introduction}

Current research in valuation studies focuses on situated practices. While there are good reasons for this orientation it may also become an obstacle, especially when "moments of valuation" (Berthoin Antal et al. 2015) are treated in isolation, and when researchers neglect the interconnectedness of moments across situations and social fields. Thus, we propose the concept of valuation constellations (Meier et al. 2016) as a general tool for analyzing valuation phenomena. Our concept of valuation constellations highlights the role of positions and relations, rules, and infrastructures, and allows for analyzing interconnected valuations. The concept provides a novel perspective for both systematic and dynamic accounts of valuation processes.

Valuation studies is mainly driven by substantive empirical research. While most studies concentrate on specific social spheres, such as the economy or science, researchers have analyzed valuation processes across a wide spectrum of fields and social forms, e.g., in face-to-face interactions, in heterarchical organizations or in large-scale technological infrastructures (for an overview, see Lamont 2012). This research conceptualizes valuation predominantly as a practice where worth is attributed to persons, goods, and performances (e.g., Heuts and Mol 2013; Kalthoff 2013; Hennion 2015; Hirschauer 2015). Indeed, opening the black box of empirical valuation practices is the main task of this fast-growing academic field.

The focus on practice also results from theoretical assumptions. Valuation studies mostly takes a "situational" stance (Stark 2009: 32; Diaz-Bone 2015: 327 ff.; Hutter and Stark 2015: 3f.) which is anchored in pragmatist social theory. Focusing on situated practices allowed authors like John Dewey $(1916,1939)$ or Luc Boltanski and Laurent Thévenot (2006) to attack the predominant concepts of value judgments of their times. Dewey, for instance, confronted notions of value as either an ejaculatory expression or as an intrinsic quality of an object with the concept of valuation as a reflexive practice (1916: 225 ff., 1939). Boltanski and Thévenot (2000: 209; see also Hennion 2004) attacked Bourdieu's (1984) notion of value judgments as determined by incorporated power relations with the concept of actors' critical capacities. For both approaches, focusing on concrete "situations" is the solution to the theoretical problems at hand (Dewey 1939: 57; Boltanski 2011: 20 ff.).

Yet in valuation studies the concept of the situation has remained vague. This is not surprising given classical definitions of the "social situation." In pragmatism, symbolic interactionism, and dramaturgical sociology, the concept of the "social situation" has a distinct empirical referent, namely interactions (Goffman 1959; Blumer 1966). Understood as interaction, the situation presents "a reality sui generis" (Goffman 1964: 134, emphasis in the original) defined by the co-presence of actors. Even though this is a precise definition, it is 
methodologically problematic since scholars struggle to define the boundaries of the situation as the object of their observation. As Karin Knorr-Cetina (1981: 11) argues, "social situations may not have a natural beginning and an end, thus forcing the researcher to choose an arbitrary cutting point." ${ }^{1}$ Situations are also not independent from the participating actors involved in the "definition of the situation," thereby making some aspects of the situation's context relevant while neglecting others (McHugh 1968; Egloff 2015). In valuation studies, most authors refrain from specifying the boundaries of situations (e.g., Diaz-Bone 2015: 328; Hutter and Stark 2015: 4). Instead, they use the concept as an umbrella term that assembles heterogeneous studies on various practices (e.g., Berthoin Antal et al. 2015).

We concur with the basic theoretical concerns of situationalism and agree that valuation always takes place operatively - and is thus temporally and spatially situated. We also agree with the assumption that any valuation process is shaped by socially generated and negotiated definitions of the situation. However, in our approach, we highlight the risks of situationalism. We emphasize that valuations may be shaped by factors that are external to the observed situations. While such external factors are often implied in the analysis or addressed in the form of ad hoc explanations, they are often not theorized. This prevents the discovery of more general patterns of valuation processes as well as systematic comparisons between different valuation practices. Furthermore, without an analytical lens that sensitizes researchers to search for these factors, they may be overlooked, especially when they are taken for granted by the participants but also by the scientific observers. Finally, it is becoming increasingly apparent that valuation situations are linked in various ways. Recently, scholars highlighted the phenomena of linked valuations and developed novel notions such as "übercapital" (Fourcade and Healy 2017), "foldings" (Helgesson 2016), or "off-label use" (Rona-Tas 2017). In this article, we present analytical tools that enable scholars to study such links in a systematic fashion.

In developing the concept of valuation constellations, we begin from the triad of valuator, valuee, and audience. This triad of positions and relations, the first component of our concept, is at the core of every valuation (i.e., every act of attributing worth to an object). It is especially important for recognizing how multiple valuations are interconnected. Yet, in valuation studies, it tends to be implied rather than analyzed.

Building on this discussion we investigate how two additional components - rules and infrastructures - shape, enable, and restrict valuations and their interconnections. The idea that valuation practices

1 This is especially true for mediated interactions in "synthetic situations" (Knorr Cetina and Brügger 2002; Knorr Cetina 2009). 
are shaped by rules transcending the immediate situation has already been suggested by some situationalist theorists, particularly by Boltanski and Thévenot (2006). In their theory of orders of worth, Boltanski and Thévenot argue that actors situationally justify and criticize by using a limited number of universally available grammars of worth. Valuations are thus enabled and constrained by certain sets of rules that are valid beyond an immediate situation. Although they deliver a rigorous analysis of conflicts and compromises between orders of worth, they neglect the question of how valuation situations actually relate to each other. As we argue, taking positions and relations into account reveals how rules are embedded in specific social contexts and guide valuations not only in situations, but across social contexts as well.

Our discussion of valuation infrastructures draws on an existing body of work that uses the concept of technological infrastructures (Star and Ruhleder 1996; Star 1999) and applies it to the field of valuation (Kornberger et al. 2017). Since infrastructures provide the material context of valuations, they are apt to facilitate links between them. ${ }^{2}$ Accordingly, valuation studies have focused on the novel capabilities of digital infrastructures to make, store, diffuse, and link valuations. To provide precise accounts of the interconnectedness of valuations, we argue that analyses of valuation infrastructures should be complemented by positions and relations as well as rules of valuations. Thus, the potential of infrastructures to connect valuations is realized in its interplay with manifold identities and rules.

In sum, we propose the concept of valuation constellations that integrates three components: positions and relations, rules, and infrastructures. We will demonstrate how these three components reveal links between moments of valuation. Moreover, we will demonstrate the usefulness of looking at these three components in concert. Because they are intricately linked, taking these components into account is key for understanding valuation and a pre-condition for transcending the limitations of situationalism.

We organize our discussion as follows: The next section introduces the general concept and its components and elaborates on the links between them. We then exemplify its analytical potential for three central problems of valuation studies: historical change of valuation processes, the definition and solution of valuation problems, and the legitimacy of valuations.

2 Boltanski and Thévenot account for the materiality of valuations by conceptualizing objects as stabilizers that help to objectify worth within a certain order (2006: 142). 


\section{Valuation Constellations}

In this section, we expand on the analytical concept of valuation constellations (Meier et al. 2016) as a theoretical tool that allows students of valuation to reflect on the interconnectedness of valuation phenomena. Throughout this article, we produce formal representations (Tilly 2004) of valuation constellations. ${ }^{3}$

A valuation constellation comprises three components that we distinguish analytically: positions - i.e., the valuator, the valuee, and the audience -, and their respective relations, rules of valuation, and infrastructures of valuation. The following discussion draws heavily on the valuation studies literature, where the three components are either explicitly discussed or at least implied. However, the first component, positions and relations, is more often assumed than systematically analyzed. For us, in contrast, it is the crucial starting point for every investigation into the worlds of valuation.

\section{Positions and Relations}

Any process or practice of valuation requires someone (or something) to articulate a valuation judgment as well as an object to which this judgment refers. Put formally, valuation establishes a relationship between two social positions - the valuator and the valuee. Positions, however, do not formulate judgments, social "identities" (Luhmann 1995; White 2008) do. ${ }^{4}$ Identities emerge from social relations (Abbott 1995; Ikegami 2000; Latour 2005). They are not bound to specific positions but may abandon and switch positions. The interplay between positions and relations on the one hand, and the movements and operations of identities on the other hand, constitutes the dynamics of any valuation process.

Most contributions to valuations studies are based on dyadic concepts of valuation. However, empirical evidence shows that the structure of valuation constellations tends to be more complex. In their study of media rankings of law schools, for example, Wendy Nelson Espeland and Michael Sauder $(2007,2016)$ demonstrate how media rankings reshaped the cultural understanding as well as the social structure of legal education in the United States - despite significant doubts regarding the appropriateness and accuracy of such assessments. The study reveals how, formally put, an object of valuation, or valuee (i.e., law schools), is forced to react to an external valuator (i.e., media ranking) to which it formerly had no important

\footnotetext{
${ }^{3}$ Formally representing constellations "oblige[s] to spell out the argument, to check its logical implications, and to examine whether the evidence conforms to the argument." It thus "promotes both visual acuity and intellectual responsibility." (Tilly 2004: 597).

4 We are deliberately unspecific about what kinds of identities are amenable to occupying those positions, as this depends on the theoretical framing of the analysis.
} 
relation. ${ }^{5}$ Law schools only started to take media rankings into account once they were taken seriously by relevant audiences, such as the board of trustees, students, or alumni (Espeland and Sauder 2016: 109). This example illustrates the significance of a third social position within valuation constellations: the audience that observes the value judgment and might base further actions and decisions on it (Sauder and Lancaster 2006). ${ }^{6}$ While valuation studies tends to focus on the dyadic relation between valuator and valuee, it is often the audience that stabilizes valuations as it forces the valuee to not only recognize the valuator's public judgment but to adapt to it.

Due to the importance of audiences, we conceptualize valuations as triads. As depicted in Figure 1, valuation constellations comprise three positions: the valuee, the valuator, and the audience. The relational structure between these positions is characterized by valuation (between valuator and value) and by observation (between audience and valuation judgment). Conceptualizing valuations this way also encourages the search for further relations relevant to the valuation which can only be established with regard to the specific identities populating the positions. For instance, some valued identities can observe their valuators (e.g., in interactions), while others cannot (e.g., on platforms); some identities' relations are further qualified by intimacy, others by dependence. The constellations perspective asks whether these relations between identities are relevant for the valuation processes at hand or for their social consequences. In the case of law school rankings mentioned above, for example, it is key to recognize the dependence of the schools on (some of) the audiences in order to understand the dynamics of reactivity.

\footnotetext{
5 The authors identify three different reactive responses to the media ranking: redistributing university resources (Espeland and Sauder 2007: 25 f.), redefining the staff's task profile (ibid.: $27 \mathrm{f}$.), and manipulating the rankings by virtue of gaming strategies, which engenders mistrust within the organizational field (ibid.: 29 ff.).

${ }^{6}$ Note that in the literature on valuation, the label of "third party" is often reserved for the valuator, which functions as an intermediary between valuee and audience (Sauder 2006; Karpik 2010).
} 


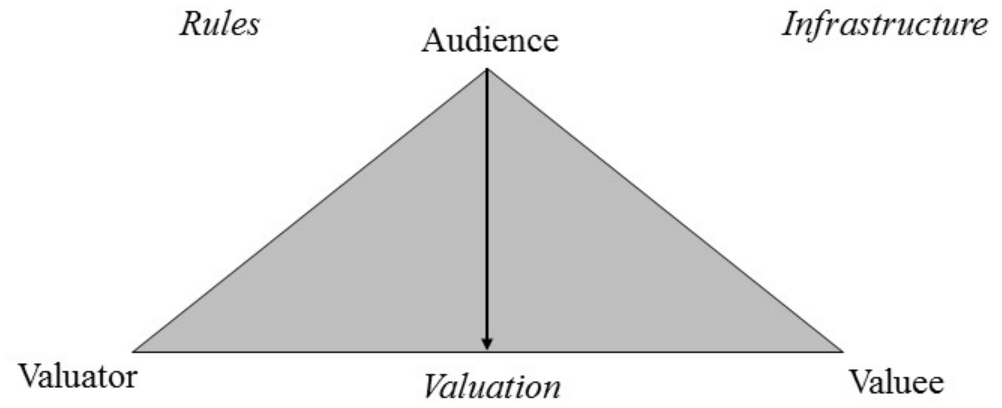

Figure 1 The valuation constellation

Source: Authors' depiction.

Formally mapping valuation triads is a helpful analytical exercise to account for the relevant identities of valuation processes as well as to disentangle the often-neglected relations between them, particularly when some of the relevant identities are barely observable in the situation. Moreover, mapping positions and relations is especially important for understanding more complex and interlinked valuation processes. In doing so, two features of valuation constellations come to the fore: positions may be populated by a plurality of identities and identities may occupy multiple positions within valuation constellations. Let us briefly discuss these two aspects.

First, mapping valuation triads sensitizes researchers to the fact that positions are often - but not always - populated by a plurality of identities. In the example of Espeland and Sauder's study, the ranking did not emerge as a valuator in a vacuum, but in a space already populated by various valuators. ${ }^{7}$ The ranking valuates its objects not in isolation but in comparison to other valuees - as is quite common in valuation practices (Espeland and Stevens 1998; Heintz 2010). Furthermore, the rankings are visible to multiple audiences, some of whom deem the judgment a "bunch of hooey" (Espeland and Sauder 2007: 13), while others based consequential decisions on it.

While situationalist accounts of valuation processes usually acknowledge the fact of plurality and reconstruct differences between both valuation practices of multiple valuators they often stop their investigation at that point. In contrast, the constellations perspective follows two methodological principles. First, that of actively searching

7 Espeland and Sauder $(2016: 49,108)$ report on professionals as well as on relatives and peers as valuators. 
for valuators, valuees, and audiences - even if they are not apparent in a given valuation situation. And second, that of looking for potential effects of plurality for both valuation practices and their consequences. For example, the constellations perspective sensitizes for the processes of competition between multiple valuators, for the different dynamics that emerge in a valuation monopoly, and for the struggles of valuators trying to meet the inconsistent expectations of multiple audiences. Overall, reconstructing the plurality of identities and their respective relations in valuations not only sharpens the view on identities - in particular on those that are overlooked, ignored, or supplanted - but it also directs attention to the dynamics that result from plurality.

Second, mapping the positions and relations of valuation triads sensitizes researchers to multipositionality, or the possibility that identities occupy multiple positions and maintain multiple relations within and across valuation triads. ${ }^{8}$ Whether multipositionality is institutionalized or not may be regarded as a distinctive characteristic of valuation processes in different social fields. In fields such as science, multipositionality is a legitimate feature of its daily business as a person regularly switches from being the audience (as a reader) to being the valuator (as a reviewer) to being the valuee (as an author). In other fields, such as law, these positions are organized in a strictly exclusive manner, and it would be illegitimate for a valuator to simultaneously occupy a valuee position, or vice-versa. ${ }^{9}$

The constellations perspective sensitizes researchers to look for how multipositional identities link distinct valuations. A good example of this is what we call the valuated valuator, where the valuation practices of a valuator are affected by the same identity's position as a valuee in another triad.

Consider the case of valuation in science. Here, as Claes-Fredrik Helgesson (2016) points out, valuated valuator-effects can emerge even in blind review processes: identities of reviewers or editors are "torn" as they squint at their own h-index, or the impact factor of their own journal, while evaluating a manuscript (see also Davis 2017). As Figure 2 shows, two valuations are linked by virtue of the multipositionality of an identity, whose practice as a valuator in one triad is shaped by the awareness of their position as a valuee in another. The anticipation of such interconnected valuations generates links to further valuations (in this case, by authors who are tempted to consider references in their manuscripts with certain editors or potential reviewers in mind).

\footnotetext{
8 For a comprehensive account on the problem of multipositionality, see Boltanski (1973, 2014: $251 \mathrm{ff}$.).

${ }^{9}$ Multipositionality has been deemed a distinct characteristic of valuation modes of different fields. For example, see Chong (2015), who distinguishes fixed- and switchrole structures in this regard, following Patrik Aspers (2008).
} 
In this way, multipositionality results in dynamics that reshuffles valuation practices in consequential ways. ${ }^{10}$

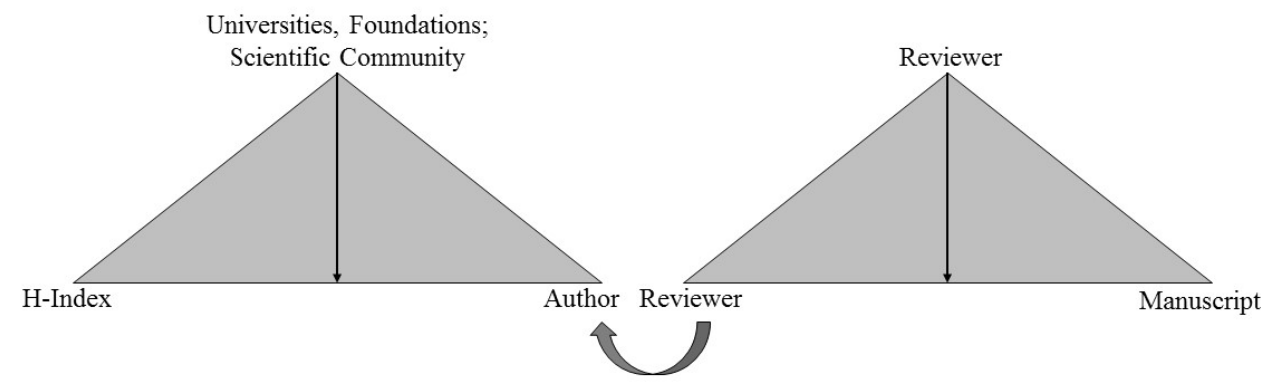

Figure 2 The valuated valuator

Source: Authors' depiction based on Helgesson (2016).

As this example shows, mapping positions and relations is helpful for studying complex, interrelated valuation processes whose links are often invisible in the immediate valuation situation. To understand the dynamics of any valuation process one must take multiple adjacent triads into account and look at how their links shape the valuation process as a whole.

\section{Rules}

Reflections on the rules that give orientation to valuation practices are an integral part of the research program of valuation studies (Dewey 1939: 20 ff.; Boltanski and Thévenot 2006; Lamont 2012). Existing research not only reconstructs these rules, but also investigates patterns and consequences of - situational - conflicts between rule sets. Rules, here broadly defined as expectations directed towards identities by themselves and by others, ${ }^{11}$ can be either formulated explicitly, like formal rules used in organizational life (Weber 1972), or implicitly as guiding practices within a given social context (Wittgenstein 2003). We distinguish three types of valuation rules. Procedural rules formulate expectations regarding the behavior of

\footnotetext{
10 For example, Espeland and Sauder (2016: 60 ff.) report that American law schools' use of their multipositionality (as valuees of the ranking, and valuators of prospective students) has substantially changed the way students are assessed by, and ultimately admitted to, their colleges.

11 This general definition of rules is translatable to concepts like "conventions" (Storper and Salais 1997: 15 ff.), "forms" (Thévenot 1984), and "institutions" (Meyer et al. 1987).
} 
identities within constellations by specifying how the attribution of worth to identities should take place. Ontological rules define the nature of identities and relations and provide broad accounts of worth; they express the practical ontologies (Meyer et al. 1987) that are used within the constellation. Finally, rules of inclusion and exclusion specify which identities are legitimate incumbents on positions within the constellation. As these are analytical distinctions, these types of rules may overlap in any given empirical rule or rule document. ${ }^{12}$

Procedural rules enable and constrain valuations; they prescribe the conditions for engaging in valuation, define valuation criteria, formulate the proper steps for it to proceed, and specify how judgments are communicated. Some procedural rules are formalized in concrete and explicit valuation programs. A good example of this is the beatification and canonization process of the Roman Catholic Church. In determining whether a deceased believer is worthy of canonization, the organization relies on programs guiding every step of the way - which is one reason why this process often takes decades (Veraja 1992; Woodward 1996). Valuation procedures are also shaped by unwritten "customary rules" that ensure valuations proceed smoothly (Lamont 2009; Lamont and Huutoniemi 2011). Informal rules are especially salient in interactional valuation settings. For example, Désirée Wilke (2016) has shown in her analysis of a string quartet's practicing sessions that members avoid articulating explicit negative evaluations and formulate their judgments in a tactful way that leaves the door open for later revisions. ${ }^{13}$

The study of valuation rules is also concerned with ontological questions. Ontologies provide general cognitive frameworks about the nature of identities and the realization of (their) worth (Meyer et al. 1987). Boltanski and Thévenot (2006) provide the most prominent discussion of ontologies within valuation studies, arguing that critique and justification are processed by virtue of a plurality of orders of worth. In light of each order, persons and objects take different shapes, and are put to test according to distinct principles of justice and accounts of grandeur. Orders of worth indicate what a given situation is about; providing classification systems for categorizing identities and specifying the signs that represent value. In this perspective, valuation situations are ontologically indeterminate as well as subject to ontological pluralism. Other authors argue that ontological pluralism derives from the different social contexts, practices, and technological infrastructures they are associated with (Bourdieu 1984; Knorr-Cetina

\footnotetext{
12 We do not claim this list to be exhaustive. Nevertheless, we argue that rules for procedures, ontologies, and inclusion cover some of the most important aspects of valuation rules.

13 In contrast, various formats of "valutainment" (Muniesa and Helgesson 2013) derive their allure precisely from breaching common rules of tactfulness.
} 
1999; Fourcade 2011; MacKenzie 2011). While the theory of universal grammars of valuation has proven fruitful, it is this latter position that is even more important for a constellations perspective: As we will discuss below (see section Signaling), valuation problems not only arise in indeterminate situations, but may also result from valuation constellations crossing the boundaries of different social contexts.

Finally, rules of inclusion and exclusion regulate which identities can, should, or must be in- or excluded as valuators, valuees, or audiences. Who or what is allowed to valuate? Which persons or objects are legitimate valuees? Which audiences are entitled to observe, and who gets chided when caught sneaking a peak?

In modern societies experts and professionals are privileged valuators. Their legitimacy derives from claims of disinterestedness and otherhood (Meyer and Jepperson 2000). It is thus not surprising that valuation studies has a specific interest in professional valuation constellations, for example in science, education, or medicine (Lamont 2009; Kalthoff 2013; Dussauge et al. 2015). However, the time when a professional judgment was contested only by another expert (Fuller 1994) is long gone (Porter 1995). Organizations, amateurs, or intelligent artefacts may gain access to valuator positions that were once reserved for professionals. This process creates a unique opportunity to study the negotiation of rules of in- and exclusion in expert valuation constellations (Eyal 2013, 2019).

But access not only to valuator positions is constrained. The position of valuees, too, is subject to rules of in- and exclusion. Who or what can be subject to valuation is often contested, especially in the case of individuals. For instance, Viviana Zelizer's (1978, 1981) historical study of life insurance reported the moral resistance against what was perceived as an economic valuation of human life, particularly in the case of children. A contemporary example is the backlash against 'Peeple', an app that allowed users to publicly judge the 'character' of a person, which forced the app's inventors to adapt the rules of inclusion (Dewey 2015). The legitimacy of judging the ascribed or achieved attributes of persons varies significantly in different substantive, as well as historical, contexts.

Who or what can be included as a valuation's audience is regulated as well. Some rules advise valuators to systematically hide their valuations from interested audiences. In the case of gossip, for instance, not only are the valuees systematically excluded from listening in, but so are audiences that might potentially convey the secret valuations (Bergmann 1993). In general, however, modern societies foster an imperative of transparency (Davis 2016: $77 \mathrm{ff}$.) which results in a trend toward increasing visibility of valuations and thus of an expansion of audiences.

The purpose of the suggested typology of rules is two-fold. First, it is simply a reminder of the scope and diversity of the rules that are 
guiding valuation and a tool for analyzing them. While investigating procedural and ontological rules is of primary concern to valuation studies, rules of inclusion and exclusion do not have the same prominence. Second, it highlights that rules are linked to positions and relations. This is perhaps most obvious in the case of rules of inclusion and exclusion.

Additionally, we want to point to the value of drawing on the two components in concert for analyzing valuations that transgress situations. A common example of this phenomenon is that of travelling judgments, which occur when value judgments that were produced in one social field are taken up by an audience for their own valuation purposes in another social field. The most prominent case of travelling judgments are consumer credit scores. By their sheer visibility and accessibility, these value judgments not only influence one's worthiness as a retail lender but as a potential worker, tenant, or even lover (Figure 3) (Fourcade and Healy 2013, 2017; Rona-Tas 2017).

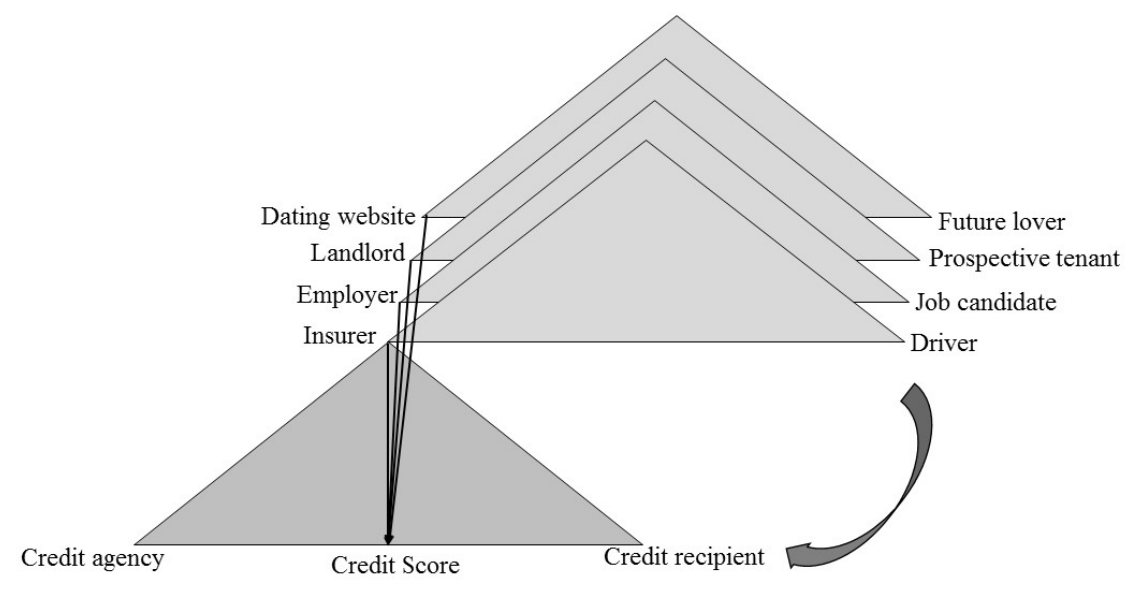

Figure 3 Travelling judgments

Source: Authors' depiction based on Fourcade and Healy (2013, 2017); Rona-Tas (2017).

Instead of taking for granted that processes of quantification result in converging valuations (Mau 2019), one should look more closely at how travelling judgments are actually linked together in different contexts (Waibel 2019). Because these contexts are populated with identities that foster their own "evaluation cultures" (MacKenzie 2011), travelling judgments are not self-evident, but instead bring about further valuation problems. For example, they require translation of the rules from their originating context as well as adaption of the rules in the receiving context. Indeed, when valuations travel, they not only evoke new procedural rules depending on the 
receiving context (Christin 2018), they are also infused with new ontological understandings (Kiviat 2017). Travelling judgments may even be rejected wholeheartedly on the basis that the rules of the originating context are not intelligible or acceptable to the identities in the new context (Christin 2017).

Procedural rules, ontologies, and rules of inclusion and exclusion are normally studied in isolated situations, where the identities involved tend to take them for granted (e.g., Lamont 2009; Rivera 2010). As we have shown with the example of travelling judgments, the constellations perspective helps to account for the importance of rules in interconnected valuations, where they guide translation, adaption, and rejection of travelling judgments.

\section{Infrastructures}

Infrastructures are another important concept for studying processes of valuation (Gerlitz 2016; Kornberger et al. 2017). Following Larkin (2013: 327) we define infrastructures as "built networks that facilitate the flow [and the valuation] of goods, people, or ideas and allow for their exchange over space." Infrastructures operate "when local practices are afforded by a larger-scale technology, which can then be used in a natural, ready-to-hand fashion" (Star and Ruhleder 1996: 114). Valuation infrastructures, by extension, facilitate, transform, stabilize, and distribute valuations. They are the material context of valuation. For valuation studies, the key question regarding infrastructures is how they constrain, enable, and shape valuation processes while they are themselves shaped by social forces.

Valuation infrastructures may look unremarkable or even "boring" (Star 1999: 379). For instance, grading in German schools relies to a high degree on pen-and-paper-based infrastructures. Among other practices of grading, teachers collect written notes about student's oral performance and transform them into symbols that allow for further calculations and the production of grades (Kalthoff 2016).

Several recent studies have analyzed the consequences of changing communication infrastructures and of the digitalization of valuation. Digitalization results in extended capacities for producing, collecting, memorizing, recollecting, and processing data (Kitchin and Dodge 2011: $7 \mathrm{ff}$.). Growing computing power and the continuous increase of bandwidth multiply the volume of data that can be used in processes of valuation. In addition, the internet is facilitating decentralized and disembedded valuations that can be used in an increasing number of interconnected calculations. Studies on internet platforms and their algorithms show (Gillespie 2014) that infrastructures participate actively in valuations. Technically, algorithms are rules for information processing. While algorithms in general can be based on different kinds 
of infrastructures, contemporary digital infrastructures allow for their automated application and modification. These algorithmic systems (Seaver 2019) provide and shape valuations in many areas of contemporary society. For instance, algorithms influence romantic matchmaking (Roscoe and Chillas 2014), calculate convicts' risk of reoffending (Angwin et al. 2016) or the life expectancies of terminally ill patients (Lobe 2017).

While the ubiquity of infrastructures attests to their importance for valuation analyses in general, from a valuation constellations perspective they are interesting for two more specific reasons. First, infrastructures are closely linked to the other two components of the constellation: identities and relations, and rules. And second, infrastructures enable or restrict linkages between valuations.

For example, infrastructures affect which identities populate the constellation's positions. A widely discussed topic is the emergence of identities that are construed by valuation infrastructures themselves. For instance, algorithmic systems serve not only as valuators, but also as audiences. Additionally, in touristic valuation, as well as literary criticism, the emergence of platforms (Gillespie 2010; Helmond 2015) like "TripAdvisor" or "Amazon.com" has enabled the participation of amateurs. This does not only undermine the jurisdiction of professional critics but also reshuffles traditional notions of excellence (Pinch and Kesler 2011; Orlikowski and Scott 2014; Beuscart et al. 2016). As we will discuss (see section Legitimacy), the valuation of these new participants is shaped by the infrastructures they depend upon.

Additionally, valuation infrastructures reflect and materially embody valuation rules. As Susan Leigh Star remarked, infrastructures are shaped by institutions (read: rules) while they are also shaping institutions (Star 1999: 381). For instance, when algorithmic systems arrange the content on platforms, their calculations are shaped by specific views of relevance. In the case of Facebook, visibility is given according to their understanding of what a valuable user is: an identity that is prone to actively participate in discussions and interactions. In turn, the "threat of invisibility" is pushing users to alter their view of relevance accordingly, and to undermine the algorithmic system by resisting its (supposed) expectations (Bucher 2012: 1175, 2017).

Finally, as they expand, valuation infrastructures open new possibilities for linking valuations, leading to complex valuation constellations and changing the rules of the game. In contemporary educational systems, for example, digital infrastructures offer new possibilities for collecting, relating, and comparing students' performance data across schools and school districts. This might result not only in 'objectified' expectations regarding learners' performance but also towards expectations regarding teachers' work. Student data are increasingly connected to teachers' data (Anagnostopoulos et al. 
2013), allowing school administrations the capacity to develop indicators and measures for evaluating teachers and their contributions to student success. Confronted with such complex valuations, mapping is essential for tracking the relevant components and checking for links between them.

\section{Linking components}

The valuation constellation perspective highlights the interconnectedness of valuations. Using this perspective sensitizes researchers to see the links between valuations by focusing on three features of valuation processes: positions and relations, rules, and infrastructures. We have developed this argument starting from positions and relations. This component of the heuristic allowed us to draw attention to the plurality of identities on the constellation's positions, their movement among those positions, as well as the fact that identities may occupy multiple positions. With the example of valuated valuators, we demonstrated the latter point, i.e., how valuation processes are shaped by the multipositionality of identities across valuations. From this starting point, we introduced two other components of valuation constellations - rules and infrastructures - and pointed out how all three components are interrelated. We conceptualize valuation rules as expectations regarding the valuation procedures, ontologies, and inclusion and exclusion. Using the notion of travelling judgments, we emphasized the role of rules in interconnected valuations. Since rules are embedded in social contexts, they play an important role in how valuations are linked across different social contexts. Finally, with valuation infrastructures, we attended to the materiality of valuations. Infrastructures are entangled with positions and relations as well as valuation rules. Not only do valuation infrastructures afford the participation of identities in novel ways, they are shaped by expectations of worth, while also shaping expectations. While infrastructures are apt to fuel links between valuations, we concluded that considering all three components is vital to analyzing how interconnections of valuations actually play out. To summarize our discussion so far, Table 1 provides an overview of the core components of the concept, their analytical foci, and examples of research questions that result from adopting the valuation constellations perspective. 
Table 1. Components of valuation constellations

\section{Valuation constellations}

\begin{tabular}{|c|c|c|c|}
\hline Components & $\begin{array}{l}\text { Positions and } \\
\text { relations }\end{array}$ & Valuation rules & $\begin{array}{c}\text { Valuation } \\
\text { infrastructures }\end{array}$ \\
\hline Definition & $\begin{array}{l}\text { Positions and } \\
\text { relations are the } \\
\text { social structure of } \\
\text { valuation } \\
\text { constellations. The } \\
\text { positions of } \\
\text { valuator, valuee, } \\
\text { and audience are } \\
\text { populated by } \\
\text { identities. }\end{array}$ & $\begin{array}{l}\text { Rules are } \\
\text { expectations that are } \\
\text { evoked in valuation } \\
\text { processes and are } \\
\text { orienting identities } \\
\text { in the constellation. }\end{array}$ & $\begin{array}{l}\text { Infrastructures are the } \\
\text { material contexts of } \\
\text { valuations that } \\
\text { facilitate, transform, } \\
\text { stabilize, and } \\
\text { distribute valuations. }\end{array}$ \\
\hline Analytical focus & $\begin{array}{l}\text { Mapping identities } \\
\text { and relations: } \\
\text { Who or what } \\
\text { occupies the } \\
\text { constellations' } \\
\text { positions? What } \\
\text { are the relevant } \\
\text { relations between } \\
\text { these identities? } \\
\text { Plural identities: } \\
\text { Are there multiple } \\
\text { identities on either } \\
\text { position? } \\
\text { Multipositionality: } \\
\text { Do identities } \\
\text { switch positions, } \\
\text { or occupy } \\
\text { multiple positions } \\
\text { at the same time? }\end{array}$ & $\begin{array}{l}\text { Procedural rules: } \\
\text { What are the proper } \\
\text { steps of the } \\
\text { valuation process? } \\
\text { Ontological rules: } \\
\text { What is the "nature" } \\
\text { of persons, things, } \\
\text { their relations, } \\
\text { actions, etc.? } \\
\text { Rules of inclusion: } \\
\text { Which identities are } \\
\text { to be included } \\
\text { within or excluded } \\
\text { from a valuation? }\end{array}$ & $\begin{array}{l}\text { Materiality: How do } \\
\text { infrastructures } \\
\text { facilitate or restrict } \\
\text { valuation? How does } \\
\text { technological change } \\
\text { impact valuation? } \\
\text { Inscription of rules in } \\
\text { infrastructure: Are } \\
\text { valuation rules } \\
\text { inscribed in } \\
\text { infrastructures? } \\
\text { In- and exclusion via } \\
\text { infrastructure: Do } \\
\text { infrastructures enable } \\
\text { the inclusion of (new) } \\
\text { identities in a } \\
\text { constellation? Do they } \\
\text { contribute to the } \\
\text { exclusion of } \\
\text { identities? Do they } \\
\text { enable the } \\
\text { construction of (new) } \\
\text { identities? }\end{array}$ \\
\hline $\begin{array}{l}\text { Interconnections } \\
\text { of valuations }\end{array}$ & $\begin{array}{l}\text { Does the valuation } \\
\text { constellation } \\
\text { include multiple } \\
\text { triads that are } \\
\text { linked via identities } \\
\text { and their relations? } \\
\text { What are the effects } \\
\text { of linked } \\
\text { valuations? }\end{array}$ & $\begin{array}{l}\text { What is the role of } \\
\text { different valuation } \\
\text { rules in valuation } \\
\text { constellations? How } \\
\text { do rules enable and } \\
\text { constrain travelling } \\
\text { judgments? How do } \\
\text { different evaluative } \\
\text { cultures coexist in } \\
\text { valuation } \\
\text { constellations? }\end{array}$ & $\begin{array}{l}\text { How do infrastructures } \\
\text { facilitate or constrain } \\
\text { links between } \\
\text { valuations? How does } \\
\text { the interplay between } \\
\text { identities, rules, and } \\
\text { infrastructure shape } \\
\text { complex valuation } \\
\text { constellations? }\end{array}$ \\
\hline
\end{tabular}

Source: Authors' work. 


\section{Analyzing valuation from a valuation constellations perspective}

To this point, we have laid out the concept of valuation constellations and made some suggestions regarding its potential to develop new perspectives on phenomena of valuation, particularly interconnected valuations. In this section, we turn to demonstrating the analytical payoffs of using the concept. In order to illustrate the wide range of empirical and analytical issues that could profit from adopting a valuation constellations perspective, we use three empirical examples to address three analytical puzzles central to valuation studies, drawing on our empirical research. First, we show that the valuation constellations perspective allows researchers to systematically account for historical changes in valuation processes by using the example of the digitalization of intimate valuation. Second, drawing on the case of signaling quality in competitive higher education systems, we show how analyses of the definition and solution of valuation problems are enhanced by taking their embeddedness in valuation constellations as the analytical frame of reference. Third and finally, we show how the valuation constellations perspective adds to studies on the legitimacy of valuations. Referring to the rise of amateur literary criticism, we propose that thinking about legitimacy should be systematically expanded to account for its role in interconnected valuation processes. In doing so, we address three important research questions of valuation studies: How does valuation change? How are problems of valuation defined and resolved? And what is the role of different views of appropriateness of valuations, i.e., of valuations of valuations?

\section{Change}

The concept of valuation constellations offers a simple but effective heuristic to analyze change in valuations by producing formal representations of valuation constellations at specific points in time. These formal representations can be used for diachronic comparisons among constellations, highlighting their similarities as well as their differences at distinct analytical levels. In order to illustrate this potential, we now turn to the case of heterosexual intimate valuation.

Valuation practices in heterosexual matchmaking have undergone significant changes in the last quarter of the twentieth century. ${ }^{14}$ Current transformations are in great part caused by infrastructural innovation. Of course, technological infrastructures are not the only possible source of change in valuation constellations. In dating,

\footnotetext{
14 We use the case of heterosexual dating as an example for change of valuation constellations knowing that it does not represent the whole universe of dating, especially other forms of desire. For accounts of contemporary transformations of homosexual dating, see, for instance, Race (2015), Licoppe et al. (2016), and Tang (2017).
} 
however, the advent of computers, the internet, and mobile phones have resulted in new opportunities for and practices of valuation. With online dating sites and mobile dating applications, the initial stages of the dating process moved online for a considerable part of the dating population (Rosenfeld and Thomas 2012; Smith and Duggan 2013). Observing this transformation from a valuation constellations perspective, one of the first analytical steps is to map the changes in positions and relations, rules, and infrastructures. While this is not the place to fully elaborate on these changes, we will briefly sketch out their central features.

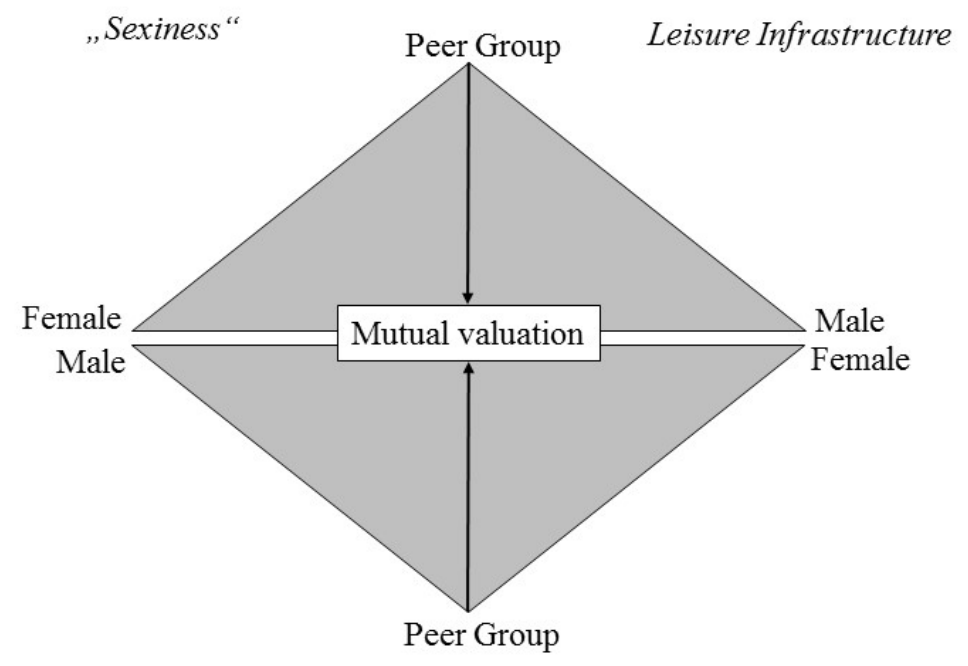

Figure 4 Modern heterosexual intimate valuation

Source: Authors' depiction based on Illouz (2012).

The transformation of intimate valuation due to (mobile) online dating should be analyzed against the background of the typical form of the valuation constellation which developed and flourished in western societies during the last century. Drawing on the work of Eva Illouz $(2007,2012)$, it is possible to characterize the constellation of modern heterosexual intimate valuation (see Figure 4). Within this constellation, male and female identities valuate each other in contexts that allow the observation of their behavior by members of their peer group (Goode 1959). These forms of valuation are embedded in a leisure infrastructure - the network of bars, dance halls, and cinemas that yields opportunities for meeting and interacting with new valuees in the absence of traditional audiences such as close relatives. As Illouz (2012) argues, within this modern environment, psychological and emotional fit as well as norms of attractiveness ("sexiness") regulate the intimate valuation of others. 


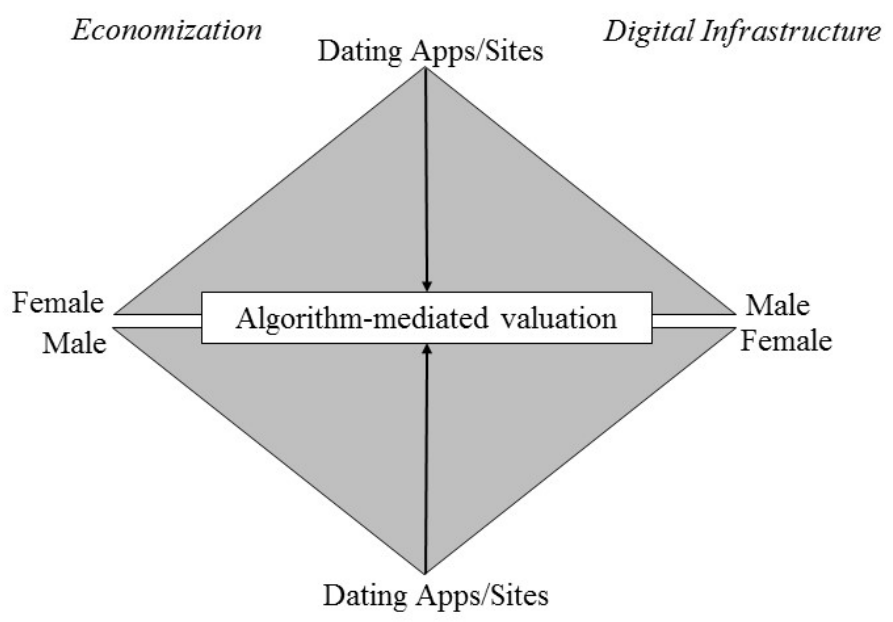

Figure 5 Heterosexual intimate valuation online

Source: Authors' compilation.

Compared to this formalization of modern dating, contemporary intimate valuation constellations look quite different (Figure 5) (see Heino et al. 2010; Finkel et al. 2012; Ranzini and Lutz 2017; Peetz 2019). Dating is increasingly removed from peer observation, especially in its initial stages. The selection of a date may now take place without the co-presence of others. Instead, dating platforms are the audiences of their members' valuation judgments. Moreover, based on their observations, they may influence the relation between valuators and valuees. For instance, Tinder - one of the most popular dating platforms - observes its members' mutual valuation, ranks identities based on their valuation by others, and uses this information for organizing the opportunity structures for matches. Research on online dating has also identified a shift in dating rules, especially with respect to ontologies. As some authors argue, identities describe their experiences on dating platforms using economic ontologies (Heino et al. 2010; Kaufmann 2012).

In the case of intimate valuations, the concept of valuation constellations is useful for substantial comparisons of valuation at different points in time. The observed changes suggest that the transformation of technological infrastructures results in shifts regarding the valuation's audience, the relation between valuator and valuee, and the ontology of dating. Based on these insights, it is possible to ask whether these shifts are related. If technological infrastructures and ontologies influence each other as students of performativity propose (Roscoe and Chillas 2014), how did this actually influence valuation practices? And how do platforms as 
audiences of intimate valuations turn their observations into valuations of their users? These and other questions may allow researchers to develop more systematic accounts of the transformations of the practices and situations embedded within intimate valuation constellations.

\section{Signaling}

The constellations perspective not only allows for mapping changes in valuation processes, it also offers a novel view on problems of valuation and their possible solutions. Both problems and solutions are often shaped by the broader constellation in which valuators, valuees, and audiences are embedded. It is thus essential to analyze them in this broader context. The question of how signals are used in valuation processes illustrates the analytical power of this approach.

Signals become important when valuators cannot observe critical qualities of a valuee directly (Spence 1973; Gambetta 2009). They are a solution for two problems: While valuators use them for dealing with the problem of uncertainty, valuees invest in them in order to give the impression that they possess certain qualities, which they may or may not have. For valuees this is particularly important vis-à-vis relevant others, i.e., identities to which they are in a relation characterized by dependence. The constellations perspective shifts the view from the dyad of valuator and valuees to the larger network of identities. With this shift the chains of linked valuations that connect multiple valuated valuators come to the fore.

In competitive higher education systems, for instance, university leaders tend to use criteria in their internal evaluation that can also be used for signaling the scientific success of their universities to relevant others - like funding agencies, private donors, government departments of science, or students. Therefore, researchers must signal qualities that their valuated valuator can use for their own signaling of quality. As a consequence, researchers do not need to convince the university leadership that they are great scientists, but rather that they can help to convince relevant others that the university excels at research.

In some countries, university leaders use the judgments of an authoritative evaluation system as signals - like those of the Research Excellence Framework (REF) in the UK (Hamann 2016). In Germany, where no such system exists, research evaluation is focused on peerreview-based third-party funding (Gerhards 2013). In particular, 'visible', externally funded large-scale research clusters are used as a criterion for the valuation of research. ${ }^{15}$ By putting pressure on scientists to acquire specific types of funding, German university

15 For the increasing importance of public third-party funding in Germany, see Hüther and Krücken (2018). 
leaders - as valuated valuators - invest in signals that can be easily observed and assessed by relevant others, such as the departments of science. The departments of science, on their part, are valuated valuators as well, preferring criteria that allow them to signal quality to their relevant others, like other departments or the electorate. Again, third-party funding and large-scale research clusters are privileged signals as they can be easily communicated to lay audiences (see Figure $6)$.

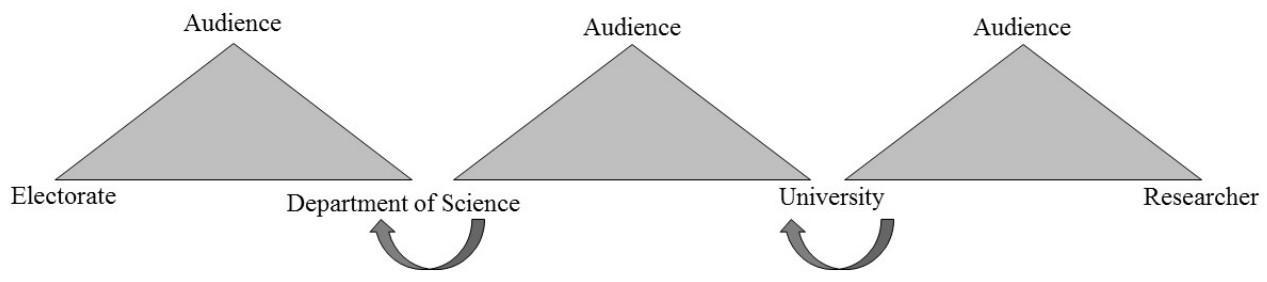

Figure 6 Signaling in competitive higher education Source: Authors' depiction.

The example of competitive higher education systems illustrates two important points. First, the constellations perspective explains the selective use of valuation criteria. Many observers assume that valuators actually believe in the adequacy of these criteria or that they are guided by the normative rules of their own field. ${ }^{16}$ Critical views on higher education tend to dismiss the use, in their view, of inadequate valuation criteria as a result of neo-liberal ideology or cognitive deficits and ignorance in university management and higher education policy. Though we have no reason to rule out the relevance of these factors categorically, these views often neglect the positions of valuated valuators in the broader networks. Even if both valuators and valuees are critical of a criterion, they might still find themselves forced to use it in order to signal value to relevant others. What can be used as a signal depends on the positions of these others in broader valuation constellations but also the valuation rules, the criteria of relevance, and the attention focus and observational capacities that guide them.

16 Of course, these as well as further arguments can support the use of a criterion: In the case of third-party funding, an argument would obviously be the resources that come with it. 
Second, the constellations perspective sensitizes researchers to the effects of long and complex signaling chains on valuation practices and offers a conceptual tool for analyzing them. Signaling chains often link heterogeneous identities and are crossing the boundaries of fields and the area of application of valuation rules. This sketch of signaling is only one example of an analytical strategy that looks for valuation problems and solutions in broader constellations rather than in narrowly defined situations. One critical imperative of the constellations perspective is then: Follow the chains!

\section{Legitimacy}

In our last example, we are going to use the valuation constellations concept to address the problem of legitimacy in complex valuation processes. A common way to analyze legitimacy in valuation studies is to examine the plethora of (often informal) rules that produce belief in the legitimacy of the valuation process (Lamont 2009: 107 ff.).17 Unsurprisingly, legitimacy tends to be taken for granted by insiders of particular valuation situations (ibid.: 242). As we have discussed in the examples of travelling judgments, however, interconnected valuations increasingly deal with multiple understandings of appropriateness concerning worth as well as valuation practices. The example of amateur book critics on Amazon.com helps illustrate how the constellations concept accounts for this problem.

In 1999, Amazon invited its customers to publish book reviews online. By essentially lifting the barrier to publication, this move radically changed the rules of inclusion in book reviewing. In the professional world, gatekeepers to publication are book review editors who select the books to be reviewed and then assign them to reviewers (Chong 2020: 20 ff.). Since identities commonly switch positions in book reviewing (reviewers are mostly authors and vice versa), editors are crucial in producing legitimacy in book valuation (Chong 2015). The lack of gatekeeping has been identified as a major flaw in book reviewing on Amazon.com. ${ }^{18}$ Indeed, it has resulted in cases of selfpraise and favor reviews (Harmon 2004). To ensure the quality of reviews, reviewers on Amazon.com are evaluated by a reviewer

\footnotetext{
17 In her programmatic call for a comparative approach to valuation, Lamont (2012) identifies legitimation as one of the sub-processes of valuation. A comparative approach sensitizes for the different and similar ways of how legitimacy is established in different valuations. In this regard Lamont and Huutoniemi (2011) compare review panels in the United States and Finland, and Chong (2013) compares scientific and artistic judgment.

18 For example, professional book critic Gail Pool (2007: 36 f.) argues that due to the lack of editorial control, reader-reviewers should not be regarded as amateur reviewers, or as legitimate reviewers at all.
} 
ranking that determines their visibility on the platform. Previously, the ranking was primarily calculated from customers' "helpful"-votes on reviews. ${ }^{19}$ This created so-called "fan votes," as some members of the audience systematically provided "helpful"-votes to the same reviewers. As Figure 7 shows, fan voting can be understood in two fundamentally different ways.

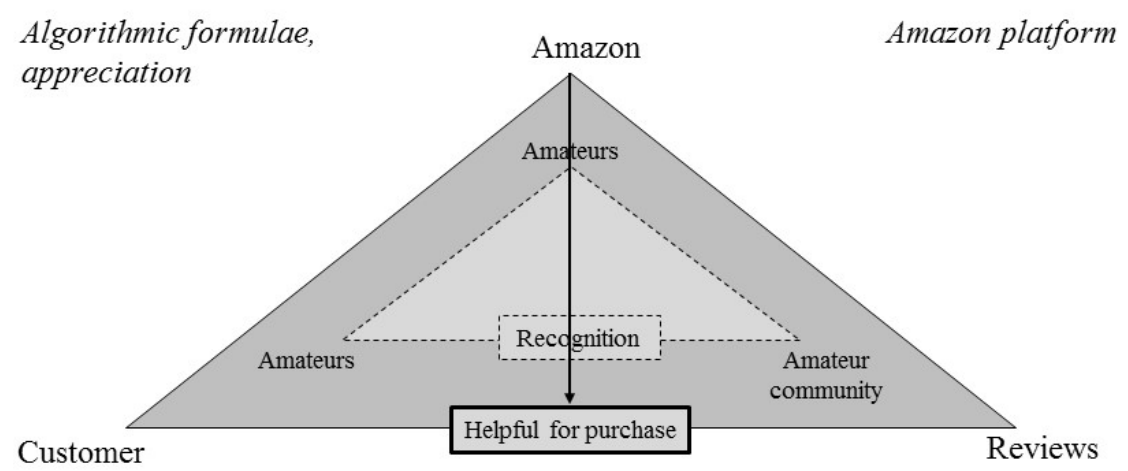

Figure 7 Valuations of reviews on Amazon.com

Source: Authors' depiction.

For Amazon, a "helpfulness"-judgment should indicate that a review is useful "to make informed purchase decisions." 20 It should be based on the comparison of the reviews listed below a product. Amateurs, however, especially self-published authors or fans of niche genres, use "helpful"-votes as a gesture of recognition of their shared passion for (otherwise neglected) books and of each other. Accordingly, the two identities hold different viewpoints on the legitimacy of fan voting. For Amazon, fan voting presents vote-stacking as a means to gain visibility, which is deemed illegitimate. For amateurs, fan voting presents a valuation of a specific community of taste, which is deemed legitimate (Pinch 2012).

Ultimately, amateurs use the infrastructure of Amazon to build a community of taste by means of a switch-role structure constellation as authors, reviewers, and audiences - whose shape is similar to

\footnotetext{
19 Note that Amazon has not disclosed its algorithmic formulae. However, when the ranking system changed drastically in 2008 , it became clear that while the old system valued quantity and stability, the new system values timeliness and the vote of the crowd (i.e., "helpful" votes) (Pinch and Kesler 2011: 56 ff.).

${ }^{20}$ See https://www.amazon.com/review/top-reviewers, accessed 15 September 2020.
} 
professional literary criticism. ${ }^{21}$ However, they also depend on Amazon, an identity that has no regard for their own views on book valuation. As the dashed lines of their valuation triad in Figure 7 visualize, amateurs hold on to their own valuation practice and can do little when their "helpful"- votes disappear, causing them to drop in rank (Pinch and Kesler 2011: 61 ff.). ${ }^{22}$

As the example of amateur book critics on Amazon.com shows, the valuation constellations perspective helps to track and explain the multiplicity of viewpoints on the appropriateness of valuations. Moreover, it highlights different means to assert those viewpoints. In this regard, asymmetries may be especially prevalent in large-scale infrastructures, which tend to decentralize control, but centralize power in the hands of the platform owner (Kornberger et al. 2017). However, the valuation constellations perspective also invites researchers to think about legitimacy more generally as valuation of valuations. In interrelated valuations, as we have seen throughout this article, these different viewpoints on the appropriateness of valuations play a crucial role in whether valuations are stabilized, interlinked, or rejected (e.g., see the example travelling judgments). This requires looking not only at the production of legitimacy in specific valuations situations, but also at how valuations are regarded from identities beyond the immediate valuation situation, what their respective means are to ignore or assert them, and consequently how such valuation of valuations shape constellations as a whole.

\section{Conclusion}

With this article, we extend the analytical toolkit of valuation studies. Moving beyond a narrow focus on practices in isolated situations, we suggest paying systematic attention to forces that may not be apparent in a moment of valuation but may nonetheless link valuations across multiple situations. To this end, we offer the conceptual framework of valuation constellations, which integrates three closely related analytical components.

The first component, positions and relations, is the key contribution of this article to the conceptual body of work of valuation studies. It directs attention to the positions of the valuator, valuee, and audience, which are populated by identities, as well as to the relations between them. By mapping positions and relations systematically, two features of valuation constellations become apparent: that the respective positions are often populated by a plurality of identities; and that

${ }^{21}$ An important difference is reciprocal reviewing, which is regarded as illegitimate in the professional world, but frequently done by amateurs.

22 Of course, one strategy is to move to another reviewing page. However, amateurs report that they are reluctant to do so, as it took them years to build their status and community on Amazon.com. 
identities may occupy multiple positions at once. As we have shown, mapping sharpens the view on relevant identities and how these identities link valuations. The second component is the rules orienting valuations within a constellation, i.e., their ontologies and more or less formalized expectations regarding procedures and inclusion. The third component is the technological infrastructures that both enable and constrain valuations. The three components of the valuation constellation are interconnected. Rules are built into infrastructures; both rules and infrastructures open up or restrict the inclusion of identities.

After elaborating the concept of valuations constellations theoretically, we have exemplified how the concept can be used as a heuristic in analyses of historical changes of valuation processes, the definition and solution of valuation problems, and the legitimacy of valuations. Our example of change in intimate valuation illustrates the usefulness of the constellations perspective for mapping large-scale historical transformations. Our examples of signaling in a higher education setting and legitimacy in platform based amateur book reviewing illustrate its capacity for helping to disentangle complex dynamics of linked valuations.

Given that the fast-growing academic field of valuation studies is driven mainly by substantive empirical research, i.e., detailed studies of specific moments of valuation, it is no surprise that there have been calls for the sociology of valuation to move towards a comparative approach (Lamont 2012). As we argue above, analyzing valuation from a constellations perspective entails a systematic reconstruction of the relations between valuators, valuees, and audiences. Based on these reconstructions it is possible to map constellations by formal representations of (possibly interrelated) triads. The concept of valuation constellations thus provides a simple tool for the comparison of different cases.

However, this approach should not be read as a preference for structural aspects over the dynamic nature of valuations. As Niklas Luhmann (1995: 45) has observed, both structure and process are temporal concepts referring to reversability (structure) and irreversability (process). The concept of valuation constellations addresses both, by scrutinizing the activities of identities on positions and their movements among the positions of the constellation or across constellations. In so doing, it provides a dynamic account of valuation. Future research may also apply our concept to elucidate and compare temporal orders of valuation processes. Constellations unfold over time; that is, they are produced and reproduced by ephemeral events. Systematically exploring the temporality of these events is essential for understanding the dynamics and consequences of valuation. For instance, valuation judgments may be anticipated beforehand or observed with a considerable time lag. Different 
audiences may - either by coincidence or systematically - register judgments at different points in time. Valuated valuators may react to an observed past valuation or to the anticipation of a future judgment. Both rules and infrastructures may have a profound impact on the temporal order by opening up or restricting timeframes, or by influencing attention. Though we do not directly address the temporality of valuation constellations beyond the issue of change in this article, the constellations perspective provides a conceptual tool that allows for temporal analyses.

Eventually, the concept will also add to the potential of valuation studies to analyze important transformations of contemporary society. As several authors have suggested, linked valuations have become increasingly relevant across different social spheres (Helgesson 2016; Fourcade and Healy 2017; Rona-Tas 2017). Some authors were quick to regard such linked valuations as signifiers of broader, unidirectional trends such as quantification, digitalization, economization, or the neoliberal polity (Lamont 2012; Miller and Power 2013; Mau 2019). However, little is known about how valuations are actually linked, and to what extent they transform more traditional processes of valuation. In this respect, the concept of valuation constellations helps to disentangle the increasingly complex interrelations of positions, relations and identities, rules, and infrastructures.

Acknowledgment: We wish to thank members of the DFG-network "On the way to a valuation society?" for their comments and critique throughout the development of this piece. We are grateful to Monika Krause as well as the anonymous reviewers for their helpful suggestions for this article in the review process, and Danny Alvord for his diligent copyediting.

\section{References}

Abbott, Andrew. 1995. “Things of Boundaries.” Social Research 62(4): 857882.

Anagnostopoulos, Dorothea, Stacey Rutledge, and Valentina Bali. 2013. "State Education Agencies, Information Systems, and the Expansion of State Power in the Era of Test-Based Accountability." Educational Policy 27(2): 217-247.

Angwin, Julia, Jeff Larson, Surya Mattu, and Lauren Kirchner. 2016. "Machine Bias: There's Software Used across the Country to Predict Future Criminals. And it's Biased against Blacks." ProPublica. https:// www.propublica.org/article/machine-bias-risk-assessments-in-criminalsentencing, accessed 17 June 2017. 
Aspers, Patrik. 2008. "Analyzing Order: Social Structure and Value in the Economic Sphere." International Review of Sociology/Revue Internationale de Sociologie 18(2): 301-316.

Bergmann, Jörg R. 1993. Discreet Indiscretions: The Social Organization of Gossip. New York: De Gruyter.

Berthoin Antal, Ariane, Michael Hutter, and David Stark (eds.) 2015. Moments of Valuation: Exploring Sites of Dissonance. Oxford: Oxford University Press.

Beuscart, Jean-Samuel, Kevin Mellet, and Marie Trespeuch. 2016. "Reactivity without Legitimacy? Online Consumer Reviews in the Restaurant Industry." Journal of Cultural Economy 9(5): 458-475.

Blumer, Herbert. 1966. "Sociological Implications of the Thought of George Herbert Mead." American Journal of Sociology 71(5): 535-544.

Boltanski, Luc. 1973. "L'espace positionnel. Multiplicité des positions institutionnelles et habitus de classe." Revue Française de Sociologie 14(1): 3-26.

Boltanski, Luc. 2011. On Critique: A Sociology of Emancipation. Cambridge: Polity Press.

Boltanski, Luc. 2014. Mysteries and Conspiracies: Detective Stories, Spy Novels and the Making of Modern Societies. Cambridge: Polity Press.

Boltanski, Luc, and Laurent Thévenot. 2000. "The Reality of Moral Expectations. A Sociology of Situated Judgement." Philosophical Explorations 3(3): 208-231.

Boltanski, Luc, and Laurent Thévenot. 2006. On Justification: Economies of Worth. Princeton, NJ: Princeton University Press.

Bourdieu, Pierre. 1984. Distinction: A Social Critique of the Judgement of Taste. Cambridge, MA: Harvard University Press.

Bucher, Taina. 2012. "Want to Be on the Top? Algorithmic Power and the Threat of Invisibility on Facebook.” New Media \& Society 14(7): 1164 1180.

Bucher, Tania. 2017. "The Algorithmic Imaginary: Exploring the Ordinary Affects of Facebook Algorithms." Information, Communication \& Society 20(1): 30-44.

Chong, Phillipa. 2013. "Legitimate Judgment in Art, the Scientific World Reversed? Maintaining Critical Distance in Evaluation." Social Studies of Science 43(2): 265-281.

Chong, Phillipa. 2015. "Playing Nice, Being Mean, and the Space in Between: Book Critics and the Difficulties of Writing Bad Reviews." In Moments of Valuation. Exploring Sites of Dissonance, edited by Ariane Berthoin Antal, Michael Hutter, and David Stark, 133-146. Oxford: Oxford University Press.

Chong, Phillipa. 2020. Inside the Critics' Circle: Book Reviewing in Uncertain Times. Princeton, NJ: Princeton University Press.

Christin, Angèle. 2017. "Algorithms in Practice: Comparing Web Journalism and Criminal Justice." Big Data and Society 4(2): 1-14. 
Christin, Angèle. 2018. "Counting Clicks: Quantification and Variation in Web Journalism in the United States and France." American Journal of Sociology 123(5): 1382-1415.

Davis, Gerald F. 2016. The Vanishing American Corporation. Navigating the Hazards of a New Economy. San Francisco, CA: Berrett-Koehler.

Davis, Phil. 2017. "Citation Cartel or Editor Gone Rogue?" The Scholarly Kitchen. https://scholarlykitchen.sspnet.org/2017/03/09/citation-cartel-oreditor-gone-rogue/, accessed 1 May 2017.

Dewey, Caitlin. 2015. "After Internet Backlash, Peeple Co-Founder Will Revise Her App to Make It 'Positive'." Washington Post 5 October. go.galegroup.com/ps/i.do? $\mathrm{p}=\mathrm{AONE} \& \mathrm{sw}=\mathrm{w} \& \mathrm{u}=$ luzern $\& \mathrm{v}=2.1 \& \mathrm{id}=$ GALE\% 7CA430759970\&it=r\&asid=db84e8ed451adb29a3613589c8be 7162, accessed 1 January 2017.

Dewey, John. 1916. "The Logic of Judgments of Practice." In Essays in Experimental Logic, edited by John Dewey, 236-271. Chicago, IL: University of Chicago Press.

Dewey, John. 1939. "Theory of Valuation.” In International Encyclopedia of Unified Science. Vol. 2, edited by Otto Neurath, 1-67. Chicago, IL: University of Chicago Press.

Diaz-Bone, Rainer. 2015. Die "Économie des conventions". Grundlagen und Entwicklungen der neuen französischen Wirtschaftssoziologie. Wiesbaden: VS Verlag für Sozialwissenschaften.

Dussauge, Isabelle, Claes-Fredrik Helgesson, and Francis Lee. 2015: Value Practices in the Life Sciences and Medicine. Oxford: Oxford University Press.

Egloff, Rainer. 2015. "Definition of the Situation: History of the Concept." In International Encyclopedia of the Social \& Behavioral Sciences, edited by James D. Wright, 19-23. Amsterdam: Elsevier.

Espeland, Wendy N., and Michael Sauder: 2007. "Rankings and Reactivity: How Public Measures Recreate Social Worlds." American Journal of Sociology 113(1): 1-40.

Espeland, Wendy N., and Michael Sauder. 2016. Engines of Anxiety: Academic Rankings, Reputation, and Accountability. New York: Russel Sage Foundation.

Espeland, Wendy N., and Mitchell L. Stevens. 1998. "Commensuration as a Social Process." Annual Review of Sociology 24: 313-343.

Eyal, Gil. 2013. "For a Sociology of Expertise: The Social Origins of the Autism Epidemic." American Journal of Sociology 118(4): 863-907.

Eyal, Gil. 2019. The Crisis of Expertise. Cambridge: Polity Press.

Finkel, Eli J., Paul W. Easwick, Benjamin R. Karney, Harry T. Reis, and Susan Sprecher. 2012. "Online-Dating: A Critical Analysis from the Perspective of Psychological Science." Psychological Science in the Public Interest 13(1): 3-66.

Fourcade, Marion. 2011. "Cents and Sensibility: Economic Valuation and the Nature of 'Nature'." American Journal of Sociology 116(6): 1721-1777. 
Fourcade, Marion, and Kieran Healy. 2013. "Classification Situations: LifeChances in the Neoliberal Era." Accounting, Organizations, and Society 38(8): 559-572.

Fourcade, Marion, and Kieran Healy. 2017. "Seeing Like a Market.” SocioEconomic Review 15(1): 9-29.

Fuller, Steve. 1994. "The Constitutively Social Character of Expertise." International Journal of Expert Systems 7(1): 51-64.

Gambetta, Diego. 2009: "Signaling:" In The Oxford Handbook of Analytical Sociology, edited by Peter Hedström and Peter Bearman, 168-194. Oxford: Oxford University Press.

Gerhards, Jürgen. 2013. "Der deutsche Sonderweg in der Messung von Forschungsleistungen." Wissenschaftspolitik im Dialog 7. Berlin: Berlin Brandenburgische Akademie der Wissenschaften.

Gerlitz, Carolin. 2016. "What Counts? Reflections on the Multivalence of Social Media Data." Digital Culture and Society 2(2): 19-38.

Gillespie, Tarleton. 2010. "The Politics of 'Platforms'.” New Media \& Society 12(3): 347-364.

Gillespie, Tarleton. 2014. "The Relevance of Algorithms." In Media Technologies. Essays on Communication, Materiality, and Society, edited by Tarleton Gillespie, Pablo J. Boczkowski, and Kirsten A. Foot, 167-194. Cambridge, MA: The MIT Press.

Goffman, Erving. 1959. The Presentation of Self in Everyday Life. New York: Anchor Books.

Goffman, Erving. 1964. "The Neglected Situation." American Anthropologist 66(6): 133-136.

Goode, William J. 1959. “The Theoretical Importance of Love.” American Sociological Review 24(1): 38-47.

Hamann, Julian. 2016. "The Visible Hand of Research Performance Assessment." Higher Education 72(2): 761-779.

Harmon, Amy. 2004. "Amazon Glitch Unmasks War of Reviewers," New York Times 14 February. https://www.nytimes.com/2004/02/14/us/ amazon-glitch-unmasks-war-of-reviewers.html, accessed 19 April 2020.

Heino, Rebecca D., Nicole B. Ellison, and Jennifer L. Gibbs. 2010. "Relationshopping: Investigating the Market Metaphor in Online Dating." Journal of Social and Personal Relationships 27(4): 427-447.

Heintz, Bettina. 2010. "Numerische Differenz. Überlegungen zu einer Soziologie des (quantitativen) Vergleichs.” Zeitschrift für Soziologie 39(3): 162-181.

Helgesson, Claes-Frederik. 2016. "Editorial Note: Folded Valuations?" Valuation Studies 4(2): 93-102.

Helmond, Anne. 2015. "The Platformization of the Web: Making Web Data Platform Ready.” Social Media + Society 1(2): 1-11.

Hennion, Antoine. 2004. "Pragmatics of Taste." In Blackwell Companion to the Sociology of Culture, edited by Mark D. Jacob, and Nancy Weiss Hanrahan, 131-145. London: Blackwell. 
Hennion, Antoine. 2015. "Paying Attention: What is Tasting Wine About?" In Moments of Valuation. Exploring Sites of Dissonance, edited by Ariane Berthoin Antal, Michael Hutter, and David Stark, 37-56. Oxford: Oxford University Press.

Heuts, Frank, and Annemarie Mol. 2013. "What is a Good Tomato? A Case of Valuing in Practice." Valuation Studies 1(2): 125-146.

Hirschauer, Stefan. 2015. "How Editors Decide. Oral Communication in Journal Peer Review." Human Studies 38(1): 37-55.

Hüther, Otto, and Georg Krücken. 2018. Higher Education in Germany. Recent Developments in an International Perspective. Cham: Springer.

Hutter, Michael, and David Stark. 2015. "Pragmatist Perspectives on Valuation: An Introduction." In Moments of Valuation. Exploring Sites of Dissonance, edited by Ariane Berthoin Antal, Michael Hutter, and David Stark, 1-12. Oxford: Oxford University Press.

Ikegami, Eiko. 2000. "A Sociological Theory of Publics: Identities and Culture as Emergent Properties in Networks." Social Research 67(4): 989-1029.

Illouz, Eva. 2007. Cold Intimacies: The Making of Emotional Capitalism. Cambridge: Polity Press.

Illouz, Eva. 2012. Why Love Hurts: A Sociological Explanation. Cambridge: Polity Press.

Kalthoff, Herbert. 2013. "Practices of Grading: An Ethnographic Study of Educational Assessment." Ethnography and Education 8(1): 89-104.

Kalthoff, Herbert. 2016. "Observing - Treating - Classifying: On the Educational Practice of Human Differentiation." Procedia - Social and Behavioral Sciences 228: 648-655.

Karpik, Lucien. 2010. Valuing the Unique. The Economics of Singularities. Princeton, NJ: Princeton University Press.

Kaufmann, Jean-Claude. 2012. Love Online. Cambridge: Polity Press.

Kitchin, Rob, and Martin Dodge. 2011. Code/Space: Software and Everyday Life. Cambridge, MA: MIT Press.

Kiviat, Barbara. 2017. "The Art of Deciding with Data: Evidence from How Employers Translate Credit Reports into Hiring Decisions." SocioEconomic Review 17(2): 283-309.

Knorr Cetina, Karin. 1981. "The Micro-Sociological Challenge of MacroSociology: Towards a Reconstruction of Social Theory and Methodology." In Advances in Social Theory and Methodology, edited by Karin Knorr-Cetina, and Aaron Cicourel, 1-48. London: Routledge.

Knorr Cetina, Karin. 1999. Epistemic Cultures. How the Sciences Make Knowledge. Cambridge, MA: Harvard University Press.

Knorr Cetina, Karin. 2009. "The Synthetic Situation: Interactionism for a Global World.” Symbolic Interaction (32): 61-87.

Knorr Cetina, Karin, and Urs Brügger. 2002. "Global Microstructures: The Virtual Societies of Financial Markets.” American Journal of Sociology 107(4): 905-950. 
Kornberger, Martin, Dane Pflueger, and Jan Mouritsen. 2017. "Evaluative Infrastructures: Accounting for Platform Organization." Accounting, Organizations and Society 60: 79-95.

Lamont, Michèle. 2009. How Professors Think: Inside the Curious World of Academic Judgment. Cambridge, MA; London: Harvard University Press.

Lamont, Michèle. 2012. "Toward a Comparative Sociology of Valuation and Evaluation.” Annual Review of Sociology 38(1): 201-221.

Lamont Michèle, and Katri I. Huutoniemi. 2011. "Comparing Customary Rules of Fairness: Evaluative Practices in Various Types of Peer Review Panels.” In Social Knowledge in the Making, edited by Charles Camic, Neil Gross, and Michèle Lamont, 209-232. Chicago, IL: University of Chicago Press.

Larkin, Brian. 2013. "The Politics and Poetics of Infrastructure." Annual Review of Anthropology 42: 327-343.

Latour, Bruno. 2005. Reassembling the Social. An Introduction to ActorNetwork-Theory. Oxford: Oxford University Press.

Licoppe, Christian, Carole Anne Rivière, and Julien Morel. 2016. "Grindr Casual Hook-ups as Interactional Achievements." New Media \& Society 18(11): 2540-2558.

Lobe, Adrian. 2017. "Der Algorithmus schlägt die letzte Stunde.” Frankfurter Allgemeine Zeitung 8 January. http://www.faz.net/aktuell/feuilleton/ $\mathrm{deb}$ a t ten/e in - a lgorith mus-soll-ueber-leben-und-todentscheiden-14606357.html, accessed 24 April 2018.

Luhmann, Niklas. 1995. Social Systems. Stanford, CA: Stanford University Press.

McHugh, David. 1968. Defining the Situation. The Organization of Meaning in Social Interaction. Indianapolis; New York: Bobbs-Merrill.

MacKenzie, Donald. 2011. "Evaluation Cultures? On Invoking 'Culture' in the Analysis of Behavior in Financial Markets." Working Paper. www.sps.ed.ac.uk/ data/assets/pdf file/0007/64564/EvalCults11.pdf, accessed 1 September 2017.

Mau, Steffen. 2019. The Metric Society. The Quantification of the Social World. Cambridge: Polity Press.

Meier, Frank, Thorsten Peetz, and Désirée Waibel. 2016. "Bewertungskonstellationen. Theoretische Überlegungen zur Soziologie der Bewertung.” Berliner Journal für Soziologie 26(3/4): 307-328.

Meyer, John W., and Ronald L. Jepperson. 2000. "The 'Actors' of Modern Society. The Cultural Construction of Social Agency." Sociological Theory 18(1): 100-120.

Meyer, John W., John Boli, and George M. Thomas. 1987. "Ontology and Rationalization in the Western Cultural Account." In Institutional Structure: Constituting State, Society, and the Individual, edited by George M. Thomas, John W. Meyer, Francisco O. Ramirez, and John Boli, 12-37. Newbury Park: Sage. 
Miller, Peter, and Michael Power. 2013. "Accounting, Organizing, and Economizing: Connecting Accounting Research and Organization Theory." Academy of Management Annals 7(1): 557-605.

Muniesa, Fabian, and Claes-Fredrik Helgesson. 2013. "Valuation Studies and the Spectacle of Valuation." Valuation Studies 1(2): 119-123.

Orlikowski, Wanda J., and Susan V. Scott. 2014. "What Happens When Evaluation Goes Online? Exploring Apparatuses of Valuation in the Travel Sector." Organization Science 25(3): 868-891.

Peetz, Thorsten. 2019. "Ausweitung der Paarungszone? Grenzverschiebungen digitalisierter Paarbildung." In Digitale Bewertungspraktiken. Für eine Bewertungssoziologie des Digitalen, edited by Jonathan Kropf, and Stefan Laser, 261-273. Wiesbaden: Springer VS.

Pinch, Trevor. 2012. "Book Reviewing for Amazon.com: How SocioTechnical Systems Struggle to Make Less from More" In Managing Overflow in Affluent Societies, edited by Barbara Czarniawska, and Orvar Löfgren, 68-88. New York and London: Routledge.

Pinch, Trevor, and Filip Kesler. 2011. "How Aunt Ammy Gets Her Free Lunch. A Study on the Top Thousand Customer Reviews at Amazon.com". http://www.freelunch.me/filecabinet, accessed 12 May 2016.

Pool, Gail. 2007. Faint Praise: The Plight of Book Reviewing in America. Columbia, MO: University of Missouri Press.

Porter, Theodore M. 1995. Trust in Numbers: The Pursuit of Objectivity in Science and Public Life. Princeton, NJ: Princeton University Press.

Race, Kane. 2015. "Speculative Pragmatism and Intimate Arrangements: Online Hook-Up Devices in Gay Life.” Culture, Health \& Sexuality 17(4): 496-511.

Ranzini, Giulia, and Christoph Lutz. 2017. "Love at First Swipe? Explaining Tinder Self-Presentation and Motives." Mobile Media \& Communication 5(1): 80-101.

Rivera, Lauren A. 2010. "Status Distinctions in Interaction: Social Selection and Exclusion at an Elite Nightclub." Qualitative Sociology 33(3): 229255.

Rona-Tas, Akos. 2017. "The Off-Label Use of Consumer Credit Ratings." Historical Social Research 42(1): 52-76.

Roscoe, Philip, and Shiona Chillas. 2014. "The State of Affairs: Critical Performativity and the Online Dating Industry." Organization 21(6): 797-820.

Rosenfeld, Michael J., and Reuben. J. Thomas. 2012. "Searching for a Mate: The Rise of the Internet as a Social Intermediary." American Sociological Review 77(4): 523-547.

Sauder, Michael. 2006. "Third Parties and Status Position: How the Characteristics of Status Systems Matter." Theory and Society 35(3): 299_ 321. 
Sauder, Michael, and Ryon Lancaster. 2006. "Do Rankings Matter? The Effects of U.S. News \& World Report Rankings on the Admissions Process of Law Schools." Law \& Society Review 40(1): 105-134.

Seaver, Nick. 2019. "Knowing Algorithms.” In DigitalSTS - A Field Guide for Science \& Technology Studies, edited by Janet Vertsi, and David Ribes, 412-422. Princeton, NJ: Princeton University Press.

Smith, Aaron, and Maeve Duggan. 2013. "Online Dating and Relationships". Pew Research Center. http://www.pewinternet.org/2013/10/21/onlinedating-relationships/, accessed 1 January 2017.

Spence, Michael. 1973. "Job Market Signaling." Quarterly Journal of Economics 87(3): 355-374.

Star, Susan L. 1999. "The Ethnography of Infrastructure." American Behavioral Scientist 43(3): 377-391.

Star, Susan L., and Karen Ruhleder. 1996. "Steps Toward an Ecology of Infrastructure: Design and Access for Large Information Spaces.” Information Systems Research 7(1): 111-134.

Stark, David. 2009. The Sense of Dissonance. Accounts of Worth in Economic Life. Princeton, NJ: Princeton University Press.

Storper, Michael, and Robert Salais. 1997. Worlds of Production: The Action Frameworks of the Economy. Cambridge, MA: Harvard University Press.

Tang, Denise Tse-Shang. 2017. "All I Get is an Emoji: Dating on Lesbian Mobile Phone App Butterfly." Media, Culture \& Society 39(6): 816-832.

Thévenot, Laurent. 1984. "Rules and Implements: Investments in Forms." Social Science Information 23(1): 1-45.

Tilly, Charles. 2004. "Observations of Social Processes and their Formal Representations." Sociological Theory 22(4): 595-602.

Veraja, Fabijan. 1992. Le cause di canonizzazione dei santi. Città del Vaticano: Libreria Editrice Vaticana.

Waibel, Désirée. 2019. "Das digitale Gehäuse der Hörigkeit kontextualisiert." Zeitschrift für Theoretische Soziologie 8(1): 108-118.

Weber, Max. 1972. Wirtschaft und Gesellschaft. 5th edn. Tübingen: Mohr Siebeck.

White, Harrison C. 2008. Identity and Control: How Social Formations Emerge. Princeton, NJ: Princeton University Press.

Wilke, Désirée. 2016: "Bewertung unter Vorbehalt. Zur Praxis der Bewertungskommunikation in einem Streichquartett.” Berliner Journal für Soziologie 26(3/4): 403-431.

Wittgenstein, Ludwig (2003): Philosophische Untersuchungen. Frankfurt/M.: Suhrkamp.

Woodward, Kenneth L. 1996. Making Saints. How the Catholic Church Determines who Becomes a Saint, who Doesn't and Why. New York: Touchstone.

Zelizer, Viviana A. 1978. "Human Values and the Market: The Case of Life Insurance and Death in 19th-Century America." American Journal of Sociology 84(3): 591-610. 
Zelizer, Viviana A. 1981. "The Price and Value of Children: The Case of Children's Insurance.” American Journal of Sociology 86(5): 1036-1056.

Désirée Waibel is a sociologist, specializing in sociological theory, the sociology of expertise, and valuation studies. Her dissertation is on contemporary amateurism. The author is a $\mathrm{PhD}$ candidate and a lecturer at SOCIUM - Research Center on Inequality and Social Policy at the University of Bremen, Germany, and a lecturer at the Distance University, Switzerland.

Thorsten Peetz is a sociologist living and working in Berlin, and currently Associate Junior Fellow at the Hanse-Wissenschaftskolleg (Institute for Advanced Study), Germany. His research interests are situated within sociological theory, economic sociology, and organization studies. Thorsten's current research addresses digital intimate valuation in online dating and religious valuation in saintmaking. In addition, he is organizing the research network "On the way to a valuation society?", funded by the Deutsche Forschungsgemeinschaft, which is scrutinizing the societal consequences of transformations in valuation.

Frank Meier is a sociologist. His research interests include valuation studies, organization studies, science studies, higher education, and sociological theory. 